\title{
An Essential Starting Point for Re-Education of Sport and Physical Activity (PA) Promotion
}

\author{
Henry Joe Tucker ${ }^{1, ~ * L u t f h i ~ A b d i l ~ K h u d d u s ~}{ }^{2,}$ Nur Ahmad Arief ${ }^{3,}$ Yongky Dwi Adi \\ Priyanto $^{4}$, Andhega Wijaya ${ }^{5}$, Youqiang $\mathrm{Li}^{6}$
}

\author{
${ }^{1}$ Department of Human Kinetics and Health Education. Njala University, Bo Campus, Sierra Leone West Africa \\ ${ }^{2}$ Department of Health Education and Recreation, Universitas Negeri Surabaya, Indonesia \\ ${ }^{3,5}$ Department of Sport Education, Universitas Negeri Surabaya, Indonesia \\ ${ }^{4}$ Physical Education and Sport, SMA Labschool Cirendeu, Universitas Negeri Jakarta, Indonesia \\ ${ }^{6}$ Department of Physical Education and sport Training, Shanghai University of Sport, Shanghai, the people's \\ Republic of China \\ *Corresponding author. Email: lutfhikhuddus@unesa.ac.id
}

\begin{abstract}
Due to the increasing global pandemic (COVID-19), sports and exercise are increasingly important in our lives. Staying in a confined environment without physical activity for months as a precaution to control or stop the spread of the virus carries many health and psychological consequences. As a result, there is a need to review sports pedagogical approaches to help enlighten citizens about the importance of sport and exercise. Sports educators must actively seek to cultivate and develop this Phenomenon. Using the "five (5) pedagogical approaches to teaching" as a framework, this article explores alternative sports pedagogical approaches as an effective means of providing re-education and opportunities to realize sport and physical activity. This research is based on the available literature, published articles, and magazines. The content is analyzed for the need for positive pedagogical influence of exercise to promote psychological, physical, healthy growth, and learning processes during this COVID-19 era. It can be concluded that coaches should develop a training plan with various learning options that explain concepts or demonstrate training methods for athletes/coaches. An "easy to find" type of work plan and training system should be training where athletes/participants can work unsupervised. Currently, people are also starting to adapt to new conditions, including doing physical activity from home. Although reviewing sports pedagogical approaches during this critical moment can be challenging, effective pedagogical strategies will be found with the collaborative efforts of sports governing bodies. The purpose of this research is to analyze methods in implementing sports education and physical activity in school.
\end{abstract}

Keywords: Confined, Physical activity, Psychological, Sport pedagogic, Phenomenon.

\section{INTRODUCTION}

Sport pedagogic is considered a favorable context for accomplishing improved physical education (PE) and physical activities (PA). However, since published research on sport pedagogic is limited, the actual scope of sport pedagogic instruction largely depends on the creative potentials of the pedagogue, which intuitively leads to the motivation of athletes/trainees. Therefore, in this article, two keywords will be at play relating to sport "pedagogic" and "pedagogy," which, according to the definition, are two sides of the same coin. According to the Cambridge online dictionary, pedagogic is; "relating to the methods and theory of teaching" [1], and pedagogy is; the study of the methods and activities of teaching.
The pedagogic approach is expressed in five (5) domains (Constructivism or the Constructivist Approach, Collaborative Approach, Inquiry-Based Approach, Integrative Approach, and Reflective Approach) [2] as guiding principles for teaching and learning. In order to assess and strengthen their practice, the knowledge and professional skills of teachers are built around pedagogy derived from a developed curriculum. Furthermore, teachers are encouraged to improve their practice according to the current trend, initiating alternatives to the face-to-face classroom scenario, which is now few and far between. Equally so, sport pedagogic actors should develop mechanisms across required components that are interrelated, gearing towards building practice and excellence. 
Fundamentally, in response to the needs of athletes/trainees' pedagogic requirements, pedagogic tasks must go along with human relationships towards achieving goals. Furthermore, teachers are expected to change from one domain to another as part of their classwork design and practice to teach and learn effectively. "There should, therefore, be an interaction between this practice and the teaching methodologies employed" [3]. In this article, sport pedagogic alternative means are sought in line with the five (5) pedagogic approaches to deeply engage in effective teaching and practice during this "awkward" period.

\section{METHODS}

This study was based on a literature search for the theoretical bases of sport pedagogic alternative approaches to help map out possible ways for effective teaching, learning, and practice of sport as the face-toface or physical contact with coaches/trainers has been severely affected by the pandemic. The search and careful selection of information in published articles and magazines allowed us to gather a set of theoretical frameworks, one of the five (5) pedagogical approaches in teaching. It also helps us identify significant concepts to ascertain alternative measures to the already existing approach of sport pedagogic [4].

\subsection{Identify guide}

keywords for the following discussion are referred to as "guidelines" and are identified based on their accessibility to and excellence in systematic review practice. In this study, ten guidance documents were identified. These documents guide various types of reviews: a review of the application of the method in sports education and a review of strategies for promoting physical activity to students. The following are the stages of a literature search in analyzing two keywords in several articles.

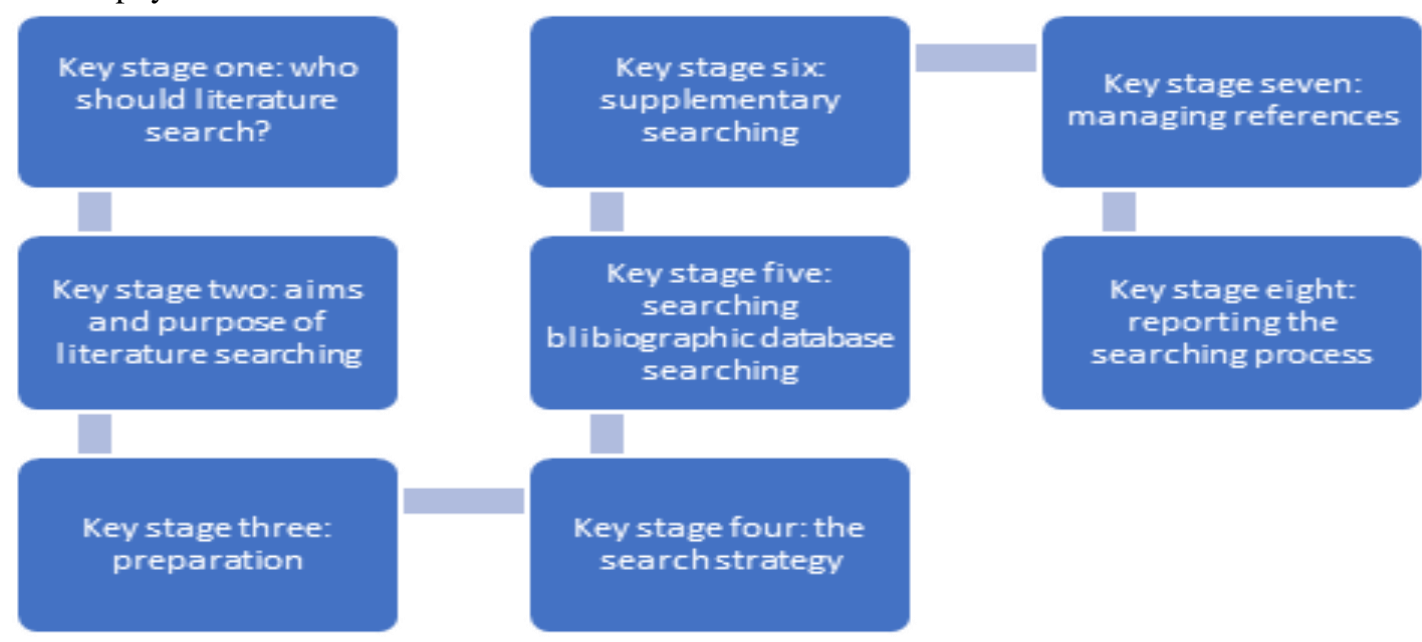

Picture 1. Stages of a literature search guide of two keywords

\subsection{Extract data}

The stage of revealing the results implicitly through a literature search in each guiding document, namely the relevant sections (chapters) in the literature search, is read and reread to determine the critical methodological stages. We define the keyword methodological stage as the distinct steps in the overall process and actions to result in a complete literature search.

The sub-chapters at each methodological stage are extracted into tables using the appropriate language as reported in each guidance document. The lead author should reread the data and paragraphs referred to by the title, summarizing more clearly in each section. The table is then reviewed, using comparisons and contrasts to identify agreements and areas of guidance. Finally, the consensus in some guidelines is used to inform the selection of 'keywords' in the literature search process.
Having determined the critical stages for the literature search, we then read and reread the sections related to the literature search again, extracting specific details relating to the methodological process of literature search in each key stage. Again, the guidelines are then read and reread, first on a document-by-document basis and, second, across the documents above, to identify commonalities and areas of guidance that give rise to uniqueness.

\section{DISCUSSION}

\subsection{Pedagogical Approaches in Teaching}

According to Guil-an, "teaching is not as easy as that because teachers must be aware of the five (5) pedagogical approaches that enhance the learning process". In other words, teachers are expected to make valid judgments as to which approach they should employ at a particular point in time. "Pedagogical skills are expressed through successful teaching and 
development, and learning through evaluations and student learning" [5]. Considering the present state of affairs in the world (COVID-19), many learning institutions are now searching for alternative methods so that learners will not be left out, as in most cases, classroom contacts are no more. However, "the realities of what can be achieved by way of commitment to a critical pedagogical approach to their careers as teachers is much more modest than the rhetoric of our aspirations" [6]. Nevertheless, the profession (teacher) itself is a noble one, and excellent opportunities exist for teachers who, from time to time, adopt the different pedagogical approaches to their teaching methodologies for effective learning.

The five (5) pedagogical approaches in teaching exist for teachers to make valid judgments about which method to adopt in a particular situation to improve learning. Adopting, therefore, one of the approaches for implementation in sport pedagogic as coaches/trainers during this critical moment can be an achieved goal moving forward. Conducting physical activity (PA) programs during this period (COVID-19) could be challenging; nevertheless, it is prudent to have scheduled activities no matter the intensity (low, medium, or high). Restrictions on the movement of people as a measure to curb the virus will lead to sedentary behavior (SB), which in effect is associated with disease conditions. For example, M. R. T. P. Menuchi et el., [7] found that sitting or reclining position for three to six hours is already sufficient to cause cardiovascular function deterioration.

To avoid such conditions, therefore, the "World Health Organization (WHO) propounded some physical activity (PA) recommendations for different age groups"; [8]

"Children and adolescents aged 5-17 years at least 60 minutes a day of moderate to vigorous-intensity physical activity (PA), and adults aged over 18 years at least 150 minutes of moderate-intensity physical activity (PA) throughout the week, or at least 75 minutes of vigorousintensity physical activity (PA) throughout the week, such as walking, cycling, doing household chores, playing sports games or exercises that have been planned" [9].

Achieving minimum physical activity (PA) levels and reducing sedentary behavior $(\mathrm{SB})$ in time of isolation becomes fundamental [7]. In that effect, the varying magnitude of physical activities (PA) at domestic levels must be sought to avoid losing the once face-to-face instructional approach given by coaches/trainers. Moreover, studies have proven that regular physical activity (PA) helps build immune systems against diseases, and COVID-19 is no exception. A concluded study by P. E. Mintarto et el. has proven the acknowledgment of people about the essence of "regular physical activity (PA) at home as an effort to maintain immunity during the COVID-19 pandemic" [9].

\subsection{Sport Pedagogy}

Sport has played an outstanding and positive role in our society today. Nista-Piccolo and Sobreira defined sport as a "sociocultural phenomenon that covers distinct dimensions and situations with a diversity of actors" [3]. Related to social activity, its impact is wide-ranging from health, economic, political, and the list goes on. Hence, there is every need for an effective and pedagogic strategy during this challenging moment to keep it going without hindrance. In that context, seeking new Pedagogical approaches to sport and physical activities (PA) are particularly critical for coaches/trainers. In another lens to understand pedagogy, Tinning says pedagogy often refers to a practice or a set of practices, the purpose of which is to pass on or produce knowledge [10]. In retrospect, according to Tinning, the practice or set of practices which was taking place between coaches/trainers and their athletes/trainees on a face-toface basis out in the playing fields, at the gym, or other designated training locations is no longer happening because of preventive measures [10].

Galati et al. "considered sport pedagogy as a discipline that aims at studying the teaching process of sports manifestations, tends to corroborate with significant and coherent changes to the suitable teaching of sports" [8]. Indeed there is now every need "to corroborate with significant and coherent changes to the suitable teaching of sports." The pandemic has brought much-untold suffering on the lives of coaches, athletes, and the entire sporting world. For example, a world event such as The Olympic Games 2020 with millions of live audiences has currently been held in a vacuum. Therefore, to meet the complex needs of athletes/trainees and physical activity (PA) enthusiasts, there is every need for a new pedagogical approach. "To teach someone to practice a sport based on a pedagogical approach is to reframe the sports phenomena" [3]. In that context, because coaches/trainers and their constituents hardly meet in person these days, we identified the "Reflective Approach" among the five (5) pedagogical approaches in teaching as a suitable alternative to replace the existing traditional relationship between the two parties.

\subsection{Reflective Approach}

Guil-an says the teacher's primary concern is the learners, and they teach in order for their students to learn something. In that light, they use some tools such as books, visuals, and any other suitable material [2]. Therefore, reasonably, and as pedagogic is; "relating to the methods and theory of teaching," sport pedagogic method should now shift from the old traditional method of coaching (face-to-face) or having direct physical 
contact with the athletes to a new theory of coaching based on reflective approach.

"Reflective teaching is a process where teachers think over their teaching practices, analyzing how something was taught and how the practice might be improved or changed for better learning outcomes. Some points of consideration in the reflection process might be what is currently being done, why it is being done, and how well students are learning. You can use reflection as a way to learn more about your practice, improve a certain practice or to focus on problem students are having" [2].

Therefore, adopting reflective teaching, sport pedagogic methods, and coaching theory should now seek suitable pedagogical strategies that are self-directing for athletes/trainees. Sports educators and coaches/trainers should reflect on the points of consideration as mentioned above "what is currently being done, why it is being done and how well students are learning," and map out online pedagogical alternatives to the face-to-face or physical contact that is currently frowned at by health practitioners. John Dewey, the great philosopher, psychologist, and education reformer (October 20, 1859June 1, 1952), [11] "believed that reflection could be beneficial for making sense of situations or events that we found puzzling or hard to explain" [12]. Realistically, at a "puzzling" moment like this, sport pedagogic actors need to have a severe reflection about which way forward so that much will not be lost.

Following that pathway, "the impulse to reflect is generated by an encounter with, and the conscious perception of, the potential significance inherent in an experience" [13] Based on an inherent experience from the former pedagogic approach, sport pedagogic instructors should now design new training packages for athletes/trainers. "It is the bridge of meaning that connects one experience to the next that gives direction and impetus to growth" [13]. "Several research studies have proved that critical reflection upon experience continues to be an effective technique for professional development" [14]. Therefore, based on previous experience, an online friendly pedagogical strategy could be of great significant value. Video contents of training instructions should be uploaded daily or as per the training schedule for athletes/trainees to be carried out. This is a possible option as a "need" at home currently, confirmed in a study by P. E. Mintarto et al. "it is essential to provide books and tutorial videos to educate people about the frequency, intensity, time, and type of physical activities according to the needs of the body and the age" [9]. The athletes/trainees, in turn, must do the same while carrying out training sessions as a feedback option and then post to the coach/trainer for evaluation.

During the evaluation, a reflective teaching methodological approach should be adopted. "The reflective teaching methodology involves questioning oneself to bring perfection by asking the following questions: Which teaching model am I using? How does it apply in specific teaching situations? How well is it working"?[14] The coach/trainer taking the role of the teacher in the case of sport pedagogic possess their knowledge, background, experience and would want to add value to the instructions. "The practice of reflective teaching explores the implication of all these complex factors with the intention of understanding and improving teaching-learning practice" [15]. In order to enhance performance, the role of the coach/trainer during this COVID-19 pandemic era must be multifaceted and not just keeping to the strict adherence of previous training regimes. "For example, according to Martens, not only do coaches need expansive technological know-how of their sport, but also the pedagogical skills of a teacher, the counseling wisdom of a psychologist, the training expertise of a physiologist, and the administrative leadership of a business executive" [16].

\subsection{Implications}

Most coaches/trainers have little online or technology experience exist for most coaches/trainers to introduce new ideas and generate multiple options to demonstrate mastery. The way and manner of introducing new ideas after every successful training session following evaluation could be a problem. Effective communication is hampered between coaches/trainers and their athletes/trainees because there is no room for on-the-spot instructions and questioning. Additionally, there are most times adverse interruptions from network (internet) providers. The environment where the athlete/trainer resides may not support the required training regime, especially in terms of appropriate training equipment and safety. Conclusively, coaches/trainers will not gauge the depth of training carried out by the athletes/trainees.

\section{CONCLUSION}

COVID-19 pandemic has undoubtedly created many problems for the sporting world; therefore, to help remedy such a situation, there must be a transition from the traditional face-to-face or physical contact between coaches/trainers and their athletes/trainees. They (coaches/trainers) must seek uniform training strategies which entail multiple options for athletes/trainees to learn and demonstrate capability. Recently, we have seen increased workload and pressure on coaches/trainers for quality and effective delivery of training instructions to their constituents. They should, however, work collaboratively to develop training plans with a variety of options for learning that explains concepts or demonstrate training regimes for the athletes/trainees. An "easy to understand" work plan and the training regime 
must be scheduled wherein athletes/trainees will be able to work unsupervised.

Moreover, coaches/trainers should design tasks without gathering that allows easy identification of errors and feedback. Most importantly, enough time must be allocated for each training session so that athletes/trainees will reflect on their training sessions and experiences as it provides excellent opportunities for improvement. Pedagogical strategy (reflective practice) is essential in knowledge acquisition (gaining new knowledge) based on previous experience. Finlay says the reflective practice is "learning through and from experience towards gaining new insights of self and practice" [17]. Complexities surrounding the prevention and control of the coronavirus create no room for specific tactical drills to be easily implemented except otherwise by special permission.

Reflection learning is a mental process that applies learning activities by activating participants to use critical thinking to examine the information obtained, ask questions about its truth, and conclude based on the ideas it generates.

Notwithstanding, we identified this pedagogical approach in teaching (reflective approach) as it attempts to make provision for gaining new knowledge of "self and practice" considering athletes/trainees working on their own from their homes based on experience, even though guided by online posted pedagogical instructions from their coaches/trainers. This reality is confirmed in research done by the article [9], which says that; nowadays, people are also starting to adapt to a new condition, including the habit of doing physical activity (PA) from home [9]. Therefore, although reviewing the sport pedagogic approach during this critical moment (COVID-19) could be challenging, effective pedagogical strategies will be found with collaborative efforts from sport governing bodies.

\section{REFERENCES}

[1] "Meaning of pedagogical in English," 2021. https://dictionary.cambridge.org/.

[2] A. Guil-an, "Five (5) Pedagogical approaches in teaching,"

2021. https://www.academia.edu/35955322/5_Pedagogical_A pproaches_in_Teaching.

[3] V. L. Nista-Piccolo and V. Sobreira, "Sports pedagogy: from initiation to sports training," sport. Coach. Rev., vol. 5, no. 2, pp. 186-188, Jul. 2016, doi: 10.1080/21640629.2016.1201352.

[4] L. de M. Beneli, M. W. Proni, and P. C. Montagner, "Desafios Para A Pedagogia Do Esporte Diante Da Influência Do Marketing No Esporte Contemporâneo," J. Phys. Educ., vol. 27, no. 1, pp. 1-14, 2016, doi: 10.4025/jphyseduc.v27i1.2750.
[5] K. A. Och and T. O. A. Ryegård, "Proving, assessing and rewarding pedagogical skills" Att belägga, bedöma och belöna pedagogisk skicklighet"," 2010. https://www.bth.se/wp-

content/uploads/2016/03/Bilaga1_pedagogisk-portföljENGELSKA-1.pdf.

[6] M. O'Sullivan and M. Parker, "Physical education teacher education in a global policy space," Curric. Stud. Heal. Phys. Educ., vol. 9, no. 1, pp. 2-6, Jan. 2018, doi: 10.1080/18377122.2018.1425119.

[7] M. R. T. P. Menuchi et al., "Physical activity and sedentary behavior adaptability to COVID-19 social and mobility constraints: a follow-up study in Ilhéus Bahia/Brazil," Brazilian J. Mot. Behav., vol. 15, no. 1, pp. 34-46, Mar. 2021, doi: 10.20338/bjmb.v15i1.212.

[8] M. P. V. C. Pereira, A. Folle, R. K. Nascimento, C. Cirino, F. J. Milan, and G. O. Farias, "Judo teaching through games: systematic organization according to the principles of complex games networks," Ido Mov. Cult., vol. 21, no. 3, pp. 1-8, 2021, doi: 10.14589/ido.21.3.1.

[9] E. Mintarto, B. A. Pramono, Y. S. Mustar, K. Ashadi, and M. Purnomo, "Need-Assessment of Physical Activity as an Effort to Increase Immunity During the Covid-19 Pandemic," 2020, doi: 10.2991/assehr.k.201201.192.

[10] R. Tinning, "Pedagogy, Sport Pedagogy, and the Field of Kinesiology," Quest, vol. 60, no. 3, pp. 405-424, Aug. 2008, doi: 10.1080/00336297.2008.10483589.

[11] M. Popova, "How We Think: John Dewey on the Art of Reflection and Fruitful Curiosity in an Age of Instant Opinions and Information Overload," 2014. https://www.brainpickings.org/2014/08/18/how-wethink-john-dewey/.

[12] "Dewey - reflection as a rationalised process," 2021. http://edshare.soton.ac.uk/.

[13] C. Rodgers, "Defining Reflection: Another Look at John Dewey and Reflective Thinking," Teach. Coll. Rec., vol. 104, no. 4, pp. 842-866, Jun. 2002, doi: 10.1111/1467-9620.00181.

[14] C. G. Navaneedhan, "Reflective teaching pedagogy as innovative approach in teacher education through open and distance learning," 2010. http://oasis.col.org/handle/11599/2224.

[15] C. G. Navaneedhan, "Reflective TeachingLearning Process of Integrating Metaphorical Thinking and Visual Imagery," J. Behav. Brain Sci., vol. 02, no. 03, pp. 407-410, 2012, doi: 10.4236/jbbs.2012.23047.

[16] R. L. Jones and P. Turner, "Teaching coaches to coach holistically: can Problem-Based Learning (PBL) help?," Phys. Educ. Sport Pedagog., vol. 11, no. 2, pp. 181-202, Jun. 2006, doi: 10.1080/17408980600708429.

[17] L. Finlay, "Reflecting on 'Reflective practice," Open Research Online, 2008. https://oro.open.ac.uk/68945/1/Finlay-\%282008\%29Reflecting-on-reflective-practice-PBPL-paper-52.pdf. 